DOI 10.37882/2223-2982.2020.10.29

\title{
МИКРОПОЛЕ ЭКСПЛИЦИТНОГО СОГЛАСИЯ В РЕЧИ РОССИЙСКОГО ПРЕЗИДЕНТА
}

\section{MICROFIELD OF EXPLICIT AGREEMENT IN RUSSIAN PRESIDENT'S SPEECH \\ T. Polyakova}

Summary: The essential minimum for identification of agreement is based on the dialogical speech. Therefore the texts of recent interviews of Russian President in national and foreign mass media are provided as a source for the scientific analysis. Agreement means confirmation, approval and acceptance of your interlocutor's words, among them V.V. Putin, journalists and politicians are introduced. In the research functional semantic field of agreement is identified and defined as system of different linguistic levels which represent the idea of agreement with its further subdivision into microfields of the second and third division levels. Using the method of functional semantic analysis functional semantic field of agreement consists of implicit and explicit microfields, and then explicit microfield is branched into discrete and indiscrete microfields of agreement. The speech and reactions of Russian President are classified on the basis of explicit to discrete agreement, i.e. in the microfields of absolute and hypothetical agreement. The main components of these microfields are modal words and modal particles. Semantic meaning of these language units illustrates various degree of agreement in real or prospective situation.

Keywords: functional semantic field, agreement, explicit, implicit, semantics, modality, interview, Putin.

\author{
Полякова Татьяна Владимировна \\ К.филол.н., доцент, Московский политехнический \\ университет \\ Anfilada1980@mail.ru
}

Аннотация: Контекст является ведущим компонентом для выявления согласия в коммуникативном акте. С этой целью в данной статье использованы тексты интервью с российским президентом на различные актуальные темы в отечественных и зарубежных средствах массовой информации. Согласие предполагает подтверждение, одобрение или поддержу слов собеседника, в их роли выступают В.В. Путин, журналисты, политические деятели и т.д. В ходе исследования выявлено и определено функционально-семантическое поле согласия как система средств различных уровней языка, отражающих идею согласия, с его последующим дроблением на микрополя второго и третьего уровня деления. С помощью метода структурно-семантического анализа функционально-семантическое поле согласия разделено на микрополя эксплицитно и имплицитного согласия, далее подлежит расслоению на микрополе дискретного и недискретного согласия. Речь и реакции российского президента проанализированы с точки зрения эксплицитного дискретного согласия, а именно: в микрополях категорического и предположительного согласия, основными конституентами которых выступают модальные слова и частицы. Семантическое значение данных языковых средств отображает различную степень согласия в рамках реальной или предполагаемой ситуации.

Ключевые слова: функционально-семантическое поле, согласие, эксплицитный, имплицитный, семантика, модальность, интервью, Путин.

согласия, в то время как над имплицитностью - его косвенное выражение. На основании указанного факта выделяется микрополе эксплицитного согласия и микрополе эксплицитного согласия [2: 81]. Исходя из метода функционально-семантического согласия, описано микрополе эксплицитно выраженного согласия. Оно подвергается более детальной классификации, в которой выделяются микрополя более низких уровней деления. Чтобы обосновать существование данных микрополей, проанализированы материалы интервью западных и отечественных СМИ с Президентом Российской Федерации, В.В. Путиным.

\section{Микрополе эксп^ишитно выраукенного согласия}

Микрополе эксплицитно выраженного согласия выделяется на основе одиннадцатого параметра семантических форм мышления «уровни формирования мысли» [3: 343]. Идея эксплицитно выраженного согласия может быть представлена конституентами микрополя дискретно выраженного согласия и микрополе недискретно вы- 
раженного согласия.

В статье предложено микрополе согласия, которое выражает идею концепта согласия, выраженного эксплицитно. Под данным явлением понимается система лингвистических составляющих различных уровней языка, в которой языковые конституенты объединяются общим значением согласия. Эксплицитное согласие представляет собой микрополе первого уровня деления, далее подлежащее делению на втором уровне на основе первого параметра семантических форм мышления. Согласно обозначенному параметру содержание коммуницируемой информации основано на степени его расчлененности при отражении действительности [4: 11-24]. Опираясь на указанный параметр, в микрополе эксплицитного согласия возможно выделить:

1. микрополе с абсолютной идеей согласия;

2. микрополе с гипотетической идеей согласия.

Существование данных микрополей обосновано включением модальности в речь коммуниканта, который отражает свою обратную связь с точки зрения одобрительных целей.

С другой стороны, микрополе эксплицитного согласия распадается на два следующих микрополя ввиду того, что концепт согласия или включает, или исключает оценку:

1. микрополе с оценочным суждением;

2. микрополе без оценочного суждения.

Суждения в данных микрополях могут носить различную степень согласия в зависимости от языковых средств, используемых коммуникантами в своей речи.

\section{Согласие через модальность}

В рамках речевого общения, которое анализируется в данной статье как функционально-семантического поле согласия, широко распространено применение модальности. Слова-реакции на реплики диалога выражают личностное отношение говорящего относительно предыдущего высказывания. Категория модальности получила широкое толкование академиком В.В. Виноградовым. Его работы, посвященные данной проблеме, имеют важное значение для современных филологов, которые тесно занимаются изучением различных направлений данной проблемы. По мнению В.В. Виноградова, «если категория предикативности выражает общую соотнесенность содержания предположения, к действительности, то отношение сообщения, содержащегося в предложении, к действительности есть прежде всего модальные отношение» [5: 325-345]. Следовательно, под идеей модального отношения понимается то, как мыслит и квалифицирует говорящий своё коммуникативное сообщение, как он относится к действительности, чтобы обеспечить действен- ность, актуальность основного средства общения [6: 10].

Если рассматривать модальность в качестве устанавливаемого говорящим отношения содержания высказывания к действительности, ученые имеют в виду отношение к действительности в рамках её достоверности в представлении говорящего. Стратегия идеи согласия заключается в положительном отношении к репликам собеседника и его речевым поступкам, что в свою очередь подразумевает одобрительный и подтверждающий характер. Работа с согласием в данном аспекте позволяет сделать вывод, что понятие согласия имеет модальный характер и может формулироваться целым набором соответствующих модальных слов и частиц.

Проблема описания модальных слов и частиц, которые выражают оценку степени достоверности высказывания, многократно привлекала внимание исследователей в традиционных грамматиках русского языка, более того данная тематика рассматривалась как самостоятельный объект исследования [7-9]. Для выражения положительной оценки реалий коммуниканты выражают идею отношения с помощью модальных слов, опираясь на собственные интенции. Данное отношение может быть заявлено в речи:

- с высокой степенью достоверности и абсолютным подтверждением (например, через модальные слова несомненно, неоспоримо, безусловно, бесспорно, точно, наверняка непременно, конечно, разумеется, естественно, действительно и др.);

- с низкой степенью достоверности или сомнением (например, через модальные слова наверное, верно, вероятно, кажется, очевидно, видимо, повидимому, видно, как видно, по всей видимости, судя по всему, пожалуй, вроде бы, будто, похоже, скорее всего, должно быть, может быть, возможно, едва ли, вряд ли, по-моему и др.).

\section{Абсолютное и гипотетическое согласие в речи В.В. Путина}

Модальные слова с предположительным значением обозначают гипотетическую модальность, поэтому согласие можно классифицировать как:

1. абсолютное или фактическое согласие, отражающее уверенность в достоверности сообщения собеседника;

2. гипотетическое или вероятное согласие, отражающее предположительность или сомнительность реальности сообщаемого.

О.Б. Добродеев: ... Политическая борьба стала существенно, гораздо жёстче, чем была до этого. В этой связи осложнит ли это ситуацию - борьбу «Единой России» за получение тех мандатов, на которые она рассчитывала для прохождения в Государственную Думу? 
В.В. Путин: Ну да, конечно, осложнит, я думаю. Борьба приобретёт более острый характер, и в целом это неплохо, наоборот, это хорошо.

В данном отрывке интервью В.В. Путина российским телеканалам в ответ на вопрос от генерального директора ВГТРК О.Б. Добродеева на тему борьбы партии «Единой России» за прохождение в Государственную Думу президент уверенно соглашается с фактом сложности данной ситуации с помощью утвердительной частицы с эмоциональным междометием ну да. Помимо этого абсолютно категорическое согласие усилено и реализовано за счет модального слова конечно.

Ч. Роуз: Однажды один из сотрудников ЦРу сказал мне, что Вы обладаете важными навыками. Вы можете очаровывать людей, и у Вас это хорошо получается. Вы их своего рода соблазняете.

В. Путин: Ну, если Вам сказали в ЦРУ, то так, наверное, оно и есть. Они специалисты неплохие.

Для выражения согласия в вышеуказанном интервью американскому журналисту Ч. Роуз В.В. Путин использует комбинацию из частиц так, наверное и есть, где частица наверное несет в себе значение предположительной истины о собственных навыках.

Два ранее предложенных примера выдержек из интервью доказывают, что в речи российского президента, присутствуют модальные слова и частицы, отражающие идею уверенного согласия с высокой степенью достоверности и идею неуверенного согласия с низкой степенью достоверности

Для выражения идеи абсолютного согласия применяются модальные слова и частицы, сформированные на базе разных частей речи:

- имена существительные (истина, правда, факт и т.д.);

O.C.: Ваши мать и отец не могли поверить в это, так?

В.П.: Это правда. Но отец не дожил буквально два месяца до того, как я был назначен премьер-министром.

В интервью Оливеру Стоуну В.В. Путин демонстрирует дискретно выраженное абсолютное согласие с помощью существительного правда, полностью поддерживая слова собеседника. Модальность слова правда носит аффирмативный характер в рассматриваемом контексте.

- краткие формы имён прилагательных (хорошо, истинно, подлинно, бесспорно, верно, точно, обязательно, действительно и т.д.);

О.С.: Вы снизили уровень бедности на две трети?

\section{В.П.: Точно.}

В данном случае идея прямого согласия, выраженная модальной частицей точно, включает в себя оценку категорически достоверной ситуации.

Вопрос: То, что Вы сейчас сказали, означает, что начиная с 1990-1991 годов, с момента распада Советского Союза, в последующие годы Россия недостаточно чётко формулировала свои национальные интересы?

\section{В. Путин: Абсолютно.}

В указанном отрывке интервью немецкому изданию Bild модальная частица абсолютно отражает эксплицитно положительную реакцию В.В. Путина на вопрос с точки зрения абсолютной релевантности действий России в отношении национальных интересов в указанный период времени.

- наречия (конечно, безусловно, действительно, правильно и т.д.);

Вопрос: Насколько я понял из Ваших высказываний, НАТО следовало бы в то время сказать восточноевропейским государствам, что оно не будет их принимать в свой состав. Как Вы думаете, НАТО смогло бы это пережить?

\section{В. Путин: Конечно.}

В данном примере наиболее распространённая модальная частица конечно в речи В.В. Путина на вопрос o HATO от немецкого издания Bild выражает согласие с фактом действительности с точки зрения возможности его существования.

- модальные глаголы (мочь, должен и т.д.).

Ч. Роуз: Как Вам хорошо известно, если Вы, как лидер этой страны, будете настаивать на верховенстве закона и справедливости, тогда можно добиться многого в плане искоренения такого негативного восприятия.

В. Путин: Можно многое, но не у всех и не всё сразу получается.

В интервью Ч. Роузу, американскому журналисту, В.В. Путин в своей ответной реакции использует повтор с помощью модальной частицы можно, которая отражает неуверенное прямое согласие с возможностью искоренения негативного восприятия в реальности. Более того, оттенок вероятности усиливается противопоставительным союзом но.

Среди модальных частиц, которые служат для выражения отношения прямого расчленённого согласия, самой распространенной является утвердительная частица - да. Она может носить характер самостоятельной реплики. 
Вопрос: Насколько я понял, Вы сложили те ошибки, которые Запад допустил в отношении Вашей страны. Как Вы считаете, Россия со своей стороны какие-то ошибки допустила за эти 25 лет?

В. Путин: Да, допустила. Мы не заявляли о своих национальных интересах, а нужно было делать это с самого начала. И тогда, может быть, мир был бы более сбалансированным.

Вопрос: Вопросы санкций, а также вопросы Крыма Вы часто обсуждали с госпожой Федеральным канцлером Ангелой Меркель. Вы понимаете её? Вы доверяете ей?

В. Путин: Да, я уверен, что она очень искренний человек. У неё есть определённые рамки, в которых она должна работать, но она искренне, и в этом я не сомневаюсь, стремится к поиску решений по урегулированию, в том числе и ситуации на юго-востоке Украины.

Для выражения идеи гипотетического согласия задействованы модальные слова, пополняющиеся за счет вводно-модальных слов (видно, очевидно, вероятно, можно, возможно, наверняка и др.).

С.СОТНИКОВ: Я надеялся, что возродится малая авиация. Все-таки надежда умирает последней.

В.ПУТИН: То есть именно исходя из соображения, что нельзя допустить разрушения полосы, поскольку Вы считали, что она будет востребована и потом будет использована?

\section{С.СОтНИКОВ: Да.}

В.ПУТИН: Хочу Вам сказать, что Вы были правы. Наверняка так и будет.

В данном отрывке из пресс-конференции В.В. Путина наверняка является средством, которое отражает прямое согласие, но допускает гипотетичность действия в будущем.

\section{Выводы}

Выше рассмотрена семантика модальных слов и частиц в контексте интервью российских и западных СМИ с В.В. Путиным. Указанные языковые средства выражают различный уровень согласия по отношению к достоверности и вероятности ситуации. Основываясь на том, что классификация модальных слов традиционно представлена двумя группами, в статье охарактеризовано два типа согласия - абсолютное и гипотетическое согласие. Из этого следует, что функционально-семантическое поле согласия в микрополе эксплицитно выраженного согласия имеет дополнительные микрополя:

- микрополе абсолютного согласия;

- микрополе гипотетического согласия.

В данной работе доказано, что согласие с точки зрения абсолютности и гипотетичности выражается модальными конституентами и имеет оттенки значений. Контекст играет важную роль в определении степени согласия. Продолжением данной работы может быть анализ речи политических лидеров других стран в сравнении с целью выявление новых способов выражения согласия и выделения новых микрополей.

\section{ЛИТЕРАТУРА}

1. Полякова Т.В. Функционально-семантическое поле согласия в современном русском языке: дис. ... канд. филол. наук. Таганрог. 146 с.

2. Полякова Т.В. Функционально-семантическое поле согласия в коммуникативном аспекте // Вестник Адыгейского государственного университета. Сер. 2: Филология и искусствоведение. Майкоп, 2018. Вып.3. С. 81-85.

3. Чесноков П.В., 2004. 0 трех типах функционально-семантического поля - онтолого-онтологическом, онтолого-гносеологическом и гносеолого-гноселогическом// Личность, речь и юридическая практика/ Выпуск 7, Ростов-н/Д. С. 342-347.

4. Чесноков П.В., 1992. Грамматика русского языка в свете теории семантических форм мышления. - Таганрог. 168 с.

5. Виноградов В.В., 1986. Русский язык. Грамматическое учение о слове. М. 639 с.

6. Бондарко А.В., 1990. Теория функциональной грамматики. Темпоральность. Модальность. М. 262 с.

7. Яковлева Е.С., 1994. Фрагменты русской языковой картины мира, М.- 343 с.

8. Добрушина Е.Р., 1994. Верификация в современной русской диалогической речи. М. 172 с.

9. Булыгина Т.В., Шмелев А.Д., 1993. Гипотеза как мыслительный акт//Логический анализ языка. Ментальные категории.М.

10. Интервью австрийскому телеканалу ORF. Доступно по ссылке: http://www.kremlin.ru/events/president/transcripts/interviews/57675.

11. Интервью немецкому изданию BILD. Часть 1. Доступно по ссылке: http://www.kremlin.ru/events/president/news/51154.

12. Полный текст интервью Путина российским телеканалам. Доступен по ссылке: https://ria.ru/politics/20111017/462204254.html.

13. Полный текст и видео интервью Владимира Путина американским СМИ. Доступен по ссылке: https://russian.rt.com/article/119789.

14. Oliver Stone. Интервью с Владимиром Путиным. Издание на русском языке, перевод, оформление. 2017.000 «Альпина Паблишер».

(c) Полякова Татьяна Владимировна (Anfilada1980@mail.ru).

Журнал «Современная наука: актуальные проблемы теории и практики» 